\title{
EDITORIAL:
}

\section{CANADIAN AND INTERNATIONAL STANDARDS FOR ANAESTHESIA EQUIPMENT}

FOR MANY YEARS anaesthetists throughout the world have been much frustrated by the diversity of products, the sizes and shapes of which were more the outgrowth of the imagination or aggressiveness of a highly competitive manufacturer than of the requirement of the consumer. More often than not the manufacturer may not have had the intimate knowledge of the finer clinical needs so necessary in the production of medical equipment. The fact that different pieces might not fit together if purchased from different sources and that sizes imprinted or implied had no real meaning were a source not only of irritation to the user but at times of definite hazard to the patient.

Recognizing these problems, anaesthetists in a number of countries some years ago began to set up working groups under the auspices of their respective national standards organizations with a view to bringing order out of chaos. The British and the Americans were first to introduce standards for endotracheal tubes and endotracheal tube connectors and in 1960 Canada established a Committee which. after several years of deliberation, also produced national standards for these two items.

Soon it became obvious, however, that even if most countries had their own standards and if all equipment were manufactured to these national requirements, there still would be no guarantee that items exported from one country to another would conform necessarily to the requirements of or would fit other parts of a circuit produced by the importing country. Therefore some six years ago a Committee was set up under the auspices of the International Standards Organization to devise international specifications on which national standards could be based and which would assure basic interchangeability of parts. This International Standards Technical Committee now has produced working drafts for both breathing attachments and endotracheal tubes, and both of these are now in the final stage of revision. They will be submitted to ISO countries within a year or so. Canada has played a leading role in these deliberations. It is clear already that Canada, the United States, Great Britain and Germany have standards which are compatible with the proposed international requirements. Thus it will be possible in the future to buy equipment in one country and be certain that it will fit other items manufactured elsewhere.

However. it must be realized that standards, both national and international, do not have the force of statute but are voluntary recommendations to manufacturers. Obriously it is in the interest of the consumer, in this case the anaesthetist and his patient. that equipment purchased should conform to these requirements but, lacking a compulsory feature, a guarantee of receiving standard equipment can be achicved only by rejecting goods not specifically manufactured to specifications. Anaesthetists should make sure that they themselves and the purchasing 
agents of their hospital have available the pertinent Canadian Standards, namely CSA Standard Z168.1 (1970) (Revised) for Tracheal Tubes and Z168.2 (1967) for Endotracheal Tube Connectors and Adaptors. Both these Standards are available from the Canadian Standards Association, 178 Rexdale Boulevard, Rexdale 603 , Ontario.

Both the American and Canadian committees are presently engaged in devising Standards for Anaesthesia Machines in the hope that this will eliminate the haphazard and sometimes dangerous sequence of flowmeters found in present-day anaesthesia machines and specify other performance requirements. The ISO technical committees are working on international specifications for respirators and on a standard nomenclature applicable to our specialty.

G.M.W. 